\title{
Genetic Variability Comparison of Wild and Cultured Far Eastern Catfish (Silurus asotus) of Korea using Microsatellite Marker
}

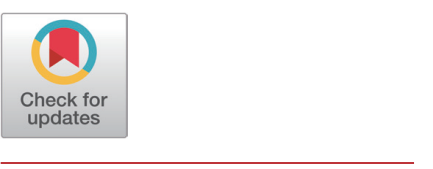

Received: October 24, 2020

Revised: October 31, 2020

Accepted: November 6, 2020

${ }^{+}$Corresponding author Jeong-Ho Lee

Inland Aquaculture Research Center, National Institute of Fisheries Science

(NIFS), Changwon 51688, Korea

Tel: $+82-55-540-2770$

Fax: +82-55-546-6292

E-mail: jhlee7124@korea.kr

Copyright $\odot 2020$ The Korean Society of Developmental Biology.

This is an Open Access article distributed under the terms of the Creative Commons Attribution Non-Commercial License (http://creativecommons.org/licenses/ by-nc/4.0/) which permits unrestricted non-commercial use, distribution, and reproduction in any medium, provided the original work is properly cited.

ORCID

Jung Eun Kim

https://orcid.org/0000-0003-4769-9093 Ju-Ae Hwang

https://orcid.org/0000-0002-7144-3162

Hyeong Su Kim

https://orcid.org/0000-0003-3189-3844

Jeong-Ho Lee

https://orcid.org/0000-0002-2236-3748

Conflict of interests

The authors declare that they have no conflict of interest.

Acknowledgements

This work was supported by a grant from the National Institute of Fisheries Science (R2020002), Korea.

Authors' contributions

Conceptualization: Kim JE, Lee JH

Data curation: Kim JE, Hwang JA

Formal analysis: Kim JE, Kim HS

Methodology: Kim JE, Lee JH

\author{
Jung Eun Kim, Ju-Ae Hwang, Hyeong Su Kim, and ${ }^{\dagger}$ Jeong-Ho Lee \\ Inland Aquaculture Research Center, National Institute of Fisheries Science (NIFS), Changwon 51688, Korea
}

\section{Abstract}

The Far Eastern catfish (Silurus asotus) is an important commercial freshwater fish in Korea. Investigation of the genetic diversity of wild and cultured domestic catfish groups is essential for the restoration of fishery resources and for increasing local revenue. However, there are relatively few genetic diversity studies on wild and cultured catfish in Korea. In the present study, we analyzed the genetic diversity and association of wild and cultured catfish using five microsatellite markers. We determined that the number of alleles per locus $\left(N_{A}\right)$ ranged from 9 to 25, wherein the Jeonbuk catfish demonstrated the highest mean number of alleles per locus and the cultured catfish exhibited the lowest. The average expected heterozygosity $(\mathrm{He})$ of the wild catfish samples was 0.907 , and that of the cultured catfish showed was 0.875 . The genetic distances (GD value) among populations of all catfish ranged from 0.138 to 0.242. Jeonnam and Jeonbuk wild catfish were located closest to each other, and the cultured group was separated from the other groups. In conclusion, the present study confirmed that the genetic diversity of wild and cultured catfish was maintained at a high level. In the case of the wild group, it is effective in maintaining diversity due to the continuous fry release by the local fish research institute. However, the genetic diversity of cultured catfish declined. Low diversity is associated with slow growth and weakened immunity, and therefore continuous monitoring is necessary.

Keywords: Far Eastern catfish, Silurus asotus, Genetic breeding, Microsatellite marker, Genetic diversity

\section{INTRODUCTION}

Far Eastern catfish (Silurus asotus), although predominantly found in Japan, China, and Northeast Asia, are widely distributed globally (Park \& Im 2001). They are important commercial freshwater fish in Korea (Kim et al., 1988; Park, 2019), and since they are more palatable than channel catfish, domestic consumption continues to increase (Lim et al., 2012). The farming production of Far Eastern catfish in Korea grossed 4269 tons in 2019, thereby making it the second largest domestically produced fish species. (Kim et al., 1988; National Statistical Office of Korea, 2020). In Korea, the catfish releasing business has remained steady since 1997, with an aim to restore fishery resources and ecosystems and to 
Writing-original draft: Kim JE

Ethics approval

This study was carried out under the permission (2017-NIFS-IACUC-13) from the National Institute of Fisheries Science (NIFS), Korea increase local resident income. However, neither the effect of the release program nor the analysis of the genetic diversity of wild catfish has been investigated. Additionally, domestic Far Eastern catfish farms produce their own seeds with limited broodstock. Continuous inbreeding has been reported to reduce growth and adaptability to environmental changes (Allendorf \& Phelps, 1980; Liu et al., 2005). However, the genetic diversity of cultured Far Eastern catfish in domestic farms has not been reported, and the study of the diversity of domestic catfish is necessary to determine the changes, if any, occurring in the population.

Microsatellite markers have been suggested as useful molecular markers for analysis of populations and genetic diversity (An et al., 2012; Kim et al., 2014). Among the DNA markers used to examine diversity at the molecular level, microsatellite DNA markers, which comprise tandem DNA repeats of two to six base pairs, are the most abundant polymorphisms (Weber \& May, 1989; Kohlmann et al., 2003; Liu \& Cordes, 2004; Alam \& Islam, 2005). These markers are extremely useful in the analysis of genetic characteristics of populations and individuals, and in the management of broodstock populations (Sekino et al., 2004).

It is essential to investigate the genetic diversity of wild domestic Far Eastern catfish to restore fishery resources and to increase local income. Additionally, the genetic diversity of cultured catfish in fish farms must be determined for continued farming. However, genetic diversity studies have not been conducted on wild and cultured catfish in Korea thus far. In this study, five microsatellite markers were used to analyze the genetic diversity and association of wild and cultured catfish in Korea.

\section{MATERIALS AND METHODS}

\section{Sample collection and DNA extraction}

A total of 203 catfish were collected, which included 65 Jeonnam wild catfish (WJN), 59 Jeonbuk wild catfish (WJB), 34 Gyeongnam wild catfish (WKN), and 45 Jeonbuk cultured catfish (Cultured) (Table 1). The fin samples (203 samples) were separated, preserved in $99.9 \%$ ethanol, and transferred to the laboratory for DNA extraction. Each sample was mixed with 5\% Chelex 100 (Bio-Rad Laboratories, Hercules, CA, USA ) and 1\% proteinase K (Roche, Basel, Switzerland) in sterile water, incubated at $55^{\circ} \mathrm{C}$ for $1 \mathrm{~h}$, and then at $100^{\circ} \mathrm{C}$ for $10 \mathrm{~min}$. The mixture was centrifuged, and the supernatant was retained. Five suitable markers were selected to distinguish the diversity in catfish. For PCR, we used primer pairs designed to amplify markers SA08, SA10, SA18, SA23, and SA42, and subjected the forward primers to fluorescent dye labeling (Table 2) (Xie et al., 2015). PCR was performed using a reaction volume of $10 \mu \mathrm{L}$ containing 100-150 ng of genomic DNA, $0.5 \mathrm{mM}$ forward and reverse primers, $0.2 \mathrm{mM}$ of dNTP (BioFact, Seoul, Korea) (Kim, 2018), 1.25 $\mathrm{U}$ of F-star Taq DNA polymerase (BioFact), 1x F-star Taq Reaction buffer (BioFact), and $1 \mu \mathrm{L}$ dimethyl sulfoxide (Sigma, St Louis, Mo, USA) (Kim, 2018). Thermal cycling was conducted with an Applied Biosystems thermal cycler (\#9902) using the following conditions: PCR was performed with 2 min denaturation at $95^{\circ} \mathrm{C}$, followed by 30 cycles of $30 \mathrm{~s}$ at $95^{\circ} \mathrm{C}, 30 \mathrm{~s}$ at the appropriate

Table 1. Country, location, code, and numbers of samples used in this study

\begin{tabular}{cccc}
\hline \hline Wild \& culture & Location & Code & No. of sample \\
\hline Wild & Jeonnam & WJN & 65 \\
Wild & Jeonbuk & WJB & 59 \\
Wild & Kyungnam & WKN & 34 \\
Culture & Jeonbuk & Cultured & 45 \\
\hline
\end{tabular}

WJN, Jeonnam wild catfish; WJB, Jeonbuk wild catfish; WKN, Gyeongnam wild catfish; Cultured, cultured from Korea. 
Table 2. Sequences of the primers used for PCR

\begin{tabular}{ccccc}
\hline \hline Marker name & Forward primer & Reverse primer & Amplicon size range & Accession number \\
\hline SA08 & AGCTTTAGCCTCAGCCTCG & CTCACTCATCAACACGGGTG & $132-174$ & LN595947 \\
SA10 & GAGAAATCCATCCTGCTGGT & CACATCCTTGTCTTGTCCACT & $140-188$ & LN592437 \\
SA18 & GTGATGGAATAACAGACAGTGAC & CTAGGACTGAAGTATGCAACTGT & $222-274$ & LN594568 \\
SA23 & GCTGAAGTCTGGTCTGCATC & CGGCTCAGTCATTAGGGCT & $264-326$ & LN590830 \\
SA42 & AATTAGGCGCGGATCGAG & AGCTTAACTGCGTGCTGT & $202-244$ & JN776311 \\
\hline
\end{tabular}

annealing temperature, and $30 \mathrm{~s}$ at $72^{\circ} \mathrm{C}$, and a final extension step at $72^{\circ} \mathrm{C}$ for $10 \mathrm{~min}$. The generated products were confirmed by $1 \%$ agarose gel electrophoresis (Kim, 2018).

\section{Genotyping}

For fragment analysis, $1 \mu \mathrm{L}$ of each PCR product was combined with formamide and a 500-LIZ size standard (GeneScan ${ }^{\mathrm{TM}} 500 \mathrm{LIZ}$; Applied Biosystems, Waltham, MA, USA), and the mixture was subjected to capillary electrophoresis using the ABI 3130 DNA Sequencer (Applied Biosystems). The GeneMapper version 4.0 fragment analysis software (Applied Biosystems) was used to determine the alleles, score, using binning in combination with manual checking, and to reveal allelic data.

\section{Statistical analysis}

The CERVUS 3.0 program (Kalinowski et al., 2007) was used to estimate the number of alleles, frequencies, expected heterozygosities, and observed heterozygosities. To test sample bias, allelic richness $\left(A_{R}\right)$, based on the minimum sample size was estimated using FSTAT (Goudet, 1995). The Bonferroni correction for multiple comparisons was applied to all $\mathrm{P}$ values obtained from multiple pairwise comparisons of FST. The Genepop 4.0 software was used to calculate inbreeding coefficient values (FIS) for all loci across all populations (Raymond \& Rousset, 1995; Rousset, 2008). The genetic distance (DCE) matrix was computed with the Arlequin software to establish the genetic distances (GDs) among samples. GDs were estimated for all population pairs based on the chord distance (Cavalli-Sforza \& Edwards, 1967). A phylogenetic tree was constructed using the unweighted pair group with the arithmetic mean (UPGMA) method, using the MEGA 5.05 software program, and bootstrap values were calculated using 1,000 replicates (Tamura et al., 2011).

\section{RESULTS AND DISCUSSION}

\section{Maintenance of a high diversity of wild catfish and reduction in the diversity of cultured catfish in Korea}

Since the genetic diversity of fish is related to environmental adaptability in aquaculture, this study evaluated the diversity of wild and farmed catfish in Korea. The genetic diversity in the three wild groups and one cultured group of $S$. asotus (total $\mathrm{N}=203$ ) was assessed using the five polymorphic microsatellite loci presented earlier (Xie et al., 2015). The measure of genetic diversity for each population, calculated from the observed allele distribution is shown in Fig. 1, and each population demonstrated presence of a few unique alleles (Fig. 1). The genetic diversity of each population is presented in Table 3. Of all of the microsatellite loci, SA42 (25) showed the highest number of alleles, whereas the lowest number was detected in SA08 (9) (Table 3). Within the wild group, the highest mean value (19.0) was observed in the WJB sample, and the lowest value (16.8) was observed in the WKN sample. Overall, the average of the cultured group (13.6) was lower than 

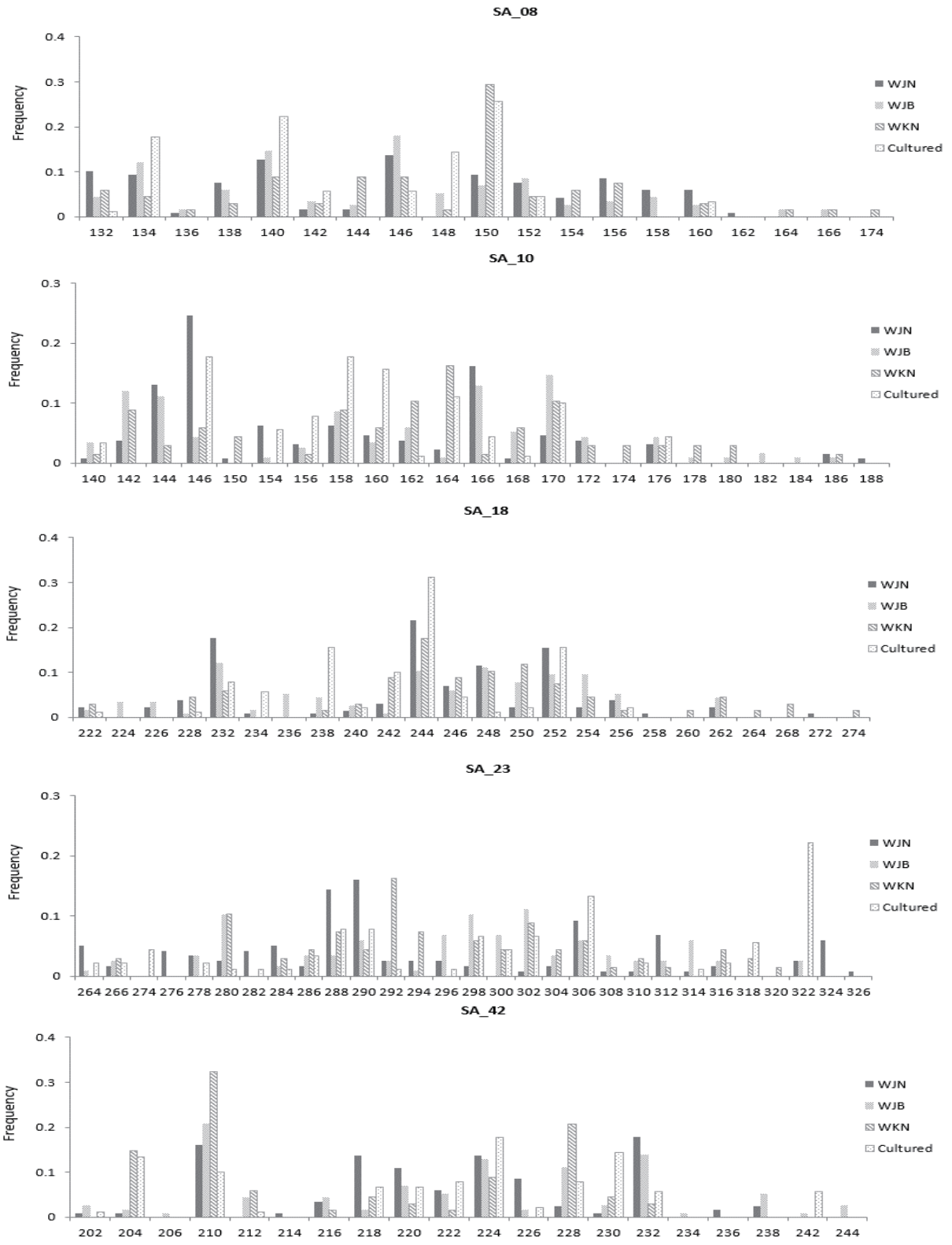

Fig. 1. Allele fragment frequency size distributions of the five microsatellite loci in the wild and cultured populations of Far Eastern catfish. WJN, Jeonnam wild catfish; WJB, Jeonbuk wild catfish; WKN, Gyeongnam wild catfish; Cultured, cultured from Korea.

that of the wild group (18.0). The allelic richness ranged from 8.738 to 21.560, and the WJN and cultured groups exhibited the highest and lowest values, respectively.

Genetic diversity is important in both wild and cultured populations, and in this study, diversity assessment was performed for both groups. The highest average number of alleles in the wild group by region was observed in the WJB sample, and the lowest number was observed in the WKN sample (Kim, 2016).However, the average of the cultured group was lower than that of the wild group. Allele richness showed similar results. Using the same marker, another study determined that wild catfish in China reported an average of 23.0 alleles (Xie et al., 2015). The Korean wild group investigated in the present study showed a relatively less number than that observed with the wild catfish in China. The 
Table 3. Summary of the results obtained from five microsatellite loci in four populations of Far Eastern catfish

\begin{tabular}{|c|c|c|c|c|c|c|}
\hline Locus & Parameter & WJN & WJB & WKN & Cultured (C) & Average \\
\hline \multirow[t]{5}{*}{ SA_08 } & $N_{A}$ & 15 & 17 & 17 & 9 & 14.5 \\
\hline & $A_{R}$ & 13.781 & 16.206 & 17.000 & 8.738 & 13.931 \\
\hline & $H_{0}$ & 0.797 & 0.759 & 0.676 & 0.511 & 0.686 \\
\hline & $\mathrm{He}$ & 0.917 & 0.912 & 0.883 & 0.833 & 0.886 \\
\hline & FIS & 0.132 & $0.169^{*}$ & 0.237 & $0.389^{*}$ & 0.232 \\
\hline \multirow[t]{5}{*}{ SA_10 } & $N_{A}$ & 18 & 20 & 19 & 12 & 17.25 \\
\hline & $A_{R}$ & 15.570 & 17.188 & 19.000 & 11.492 & 15.813 \\
\hline & $H_{0}$ & 0.754 & 0.966 & 0.735 & 0.978 & 0.858 \\
\hline & $\mathrm{He}$ & 0.884 & 0.919 & 0.932 & 0.886 & 0.905 \\
\hline & FIS & $0.148^{*}$ & -0.051 & $0.214^{*}$ & -0.105 & 0.052 \\
\hline \multirow[t]{5}{*}{ SA_18 } & $N_{A}$ & 18 & 18 & 18 & 13 & 16.75 \\
\hline & $A_{R}$ & 15.243 & 16.680 & 18.000 & 12.090 & 15.503 \\
\hline & $H_{0}$ & 0.846 & 0.879 & 0.853 & 0.711 & 0.822 \\
\hline & $\mathrm{He}$ & 0.880 & 0.930 & 0.924 & 0.841 & 0.894 \\
\hline & FIS & $0.039^{*}$ & $0.055^{\star}$ & 0.078 & $0.156^{*}$ & 0.082 \\
\hline \multirow[t]{5}{*}{ SA_23 } & $N_{A}$ & 25 & 22 & 19 & 21 & 21.75 \\
\hline & $A_{R}$ & 21.560 & 20.452 & 19.000 & 19.225 & 20.059 \\
\hline & $H_{0}$ & 0.814 & 0.621 & 0.882 & 0.956 & 0.818 \\
\hline & $\mathrm{He}$ & 0.929 & 0.943 & 0.938 & 0.911 & 0.930 \\
\hline & FIS & 0.126 & $0.344^{*}$ & 0.060 & -0.050 & 0.120 \\
\hline \multirow[t]{5}{*}{ SA_42 } & $N_{A}$ & 15 & 18 & 11 & 13 & 14.25 \\
\hline & $A_{R}$ & 12.949 & 16.016 & 11.000 & 12.452 & 13.104 \\
\hline & $H_{0}$ & 0.831 & 0.948 & 0.735 & 0.911 & 0.856 \\
\hline & $\mathrm{He}$ & 0.887 & 0.900 & 0.826 & 0.902 & 0.879 \\
\hline & FIS & 0.065 & -0.055 & 0.112 & -0.010 & 0.028 \\
\hline \multirow[t]{4}{*}{ Average } & $N_{A}$ & 18.2 & 19 & 16.8 & 13.6 & - \\
\hline & $A_{R}$ & 15.821 & 17.308 & 16.800 & 12.799 & \\
\hline & $H_{0}$ & 0.808 & 0.835 & 0.776 & 0.813 & \\
\hline & $\mathrm{He}$ & 0.899 & 0.921 & 0.901 & 0.875 & \\
\hline
\end{tabular}

${ }^{*} p<0.05$. Table-wide significance levels were applied using the sequential Bonferroni technique.

WJN, Jeonnam wild catfish; WJB, Jeonbuk wild catfish; WKN, Gyeongnam wild catfish; Cultured, cultured from Korea; $N_{A}$, number of alleles; $A_{R}$, allelic richness; $H_{0}$, observed heterozygosity; $H_{\Theta}$, expected heterozygosity; $F I S$, inbreeding coefficient.

wild group in Korea was not as diverse as the Chinese wild samples, but the diversity was comparable to the general wild common carp family $\left(N_{A}, 16-26\right)$ (Biba et al., 2015; Ghelichpour et al., 2013). According to a previous study, mortality was reported to occur frequently in groups with $N_{A}$ values ranging from 5 to 9 in the cultured group (Mondol et al., 2006). The diversity of domestic farm groups in our study did not show a value that would exhibit fatality of the species, but it continued to decrease; hence, caution should be exercised to maintain this diversity.

Observed heterozygosity $\left(H_{0}\right)$ and expected heterozygosity $(H e)$ were analyzed to investigate the diversity of genotypes and alleles in the population. The average $H_{O}$ value for each microsatellite locus was 0.808 , with the lowest value at 0.511 (SA08), and the highest value at 0.966 (SA10).

The group with the lowest average $H_{0}$ value for each wild-cultured group was WKN (0.776), and the highest $H_{O}$ value was observed in WJB (0.835). Comparison of the $H_{O}$ values of the wild and cultured groups revealed that the cultured group value (0.813) was lower than that of the wild WJB 
(0.835) and was higher than that of both the wild WJN (0.808) and WKN (0.776). The average He level was 0.899; the lowest $H e$ locus for each microsatellite locus was 0.826 at SA42, and the highest was 0.943 at SA23. Among the mean $H e$ values for each wild group, the lowest wild group was WJN (0.899), and the highest $H e$ value was WJB (0.835). Upon comparing the average $H e$ values of the wild and cultured groups, it was observed that the cultured group value (0.875) was lower than that of all wild groups (0.907). The average values of $H_{O}$ and $H e$ of wild catfish of the same marker were reported as 0.862 and 0.946 , respectively (Xie et al., 2015). Overall, the $H_{O}$ and $H e$ values are considered high in both the wild and cultured groups; however, the number of members of the cultured group continues to decline more rapidly compared to the wild group. This indicates the decreasing genetic diversity in cultured groups. Decreased genetic diversity in cultured groups has been reported to be a factor which reduces adaptability to diseases along with the growth rate (Kincaid 1983; Beardmore et al., 1997). The reduction in genetic diversity has been reported to occur with less broodstock participation (Carvalho \& Hauser, 1994). Broodstock with unique alleles failed to participate in seed production. As a result, unique alleles are lost and diversity is reduced, as illustrated in Fig. 1.

The Wrights inbreeding coefficient (FIS) was -0.105 to 0.389 . Particularly, the cultured group demonstrated the significantly highest value at 0.389 (SA08), and the WJN group exhibited the lowest value at 0.039 (SA18). The FIS value of the wild group was as low as 0.039 with respect to the SA18 marker, and inbreeding was relatively low compared to the general wild species (0.0898) (Kim et al., 2015). The FIS was as high as 0.389 in the cultured group, and this has been shown to exert an effect on the reduction of diversity (Kim et al., 2015).

\section{Wild catfish in Jeonnam and Jeonbuk demonstrate close genetic distance, and wild and cultured groups exhibit remote genetic distance}

Genetic variation between the wild and cultured groups was estimated by calculating pairwise FST values. The WJN and WJB groups showed the least genetic difference with an FST of 0.015, and the WJB and cultured groups showed the greatest genetic difference at 0.034 (Table 4). Based on results of GD analysis, the WJN and WJB groups showed the closest GD at 0.138 , and the cultured and WKN groups showed the farthest GD at 0.242 . The phylogenetic tree was determined between the groups using the UPGMA method with GD values, and WJN and WJB were found to be located close to each other; in contrast, the cultured group was distinct and separated from others.

Pairwise FST analysis and GD analysis were performed to confirm the relationship between the groups. The results showed that the WJN and WJB groups had the lowest FST values and significantly less differentiation. In contrast, the cultured and wild groups showed the most considerable differences $(p<0.05)$. Similar results were observed in the GD analysis; the WJN and WJB groups showed the closest GD, and the cultured and WKN groups showed the farthest GD. The results of the phylogenetic tree between groups obtained by using the UPGMA method were similar (Fig. 2). Research institutes in Jeonnam, Jeonbuk, and Gyeongnam continue to conduct

Table 4. Pairwise comparisons of genetic distance (upper) and FST (lower) between populations of Far Eastern catfish

\begin{tabular}{ccccc}
\hline \hline Variable & WJN & WJB & WKN & Cultured \\
\hline WJN & - & 0.1383 & 0.2173 & 0.2324 \\
WJB & $0.0152^{*}$ & - & 0.1569 & 0.2266 \\
WKN & $0.0326^{*}$ & $0.0163^{*}$ & - & 0.2420 \\
Cultured & $0.0328^{*}$ & $0.0342^{*}$ & $0.0318^{*}$ & - \\
\hline
\end{tabular}

${ }^{*} p<0.05$.

WJN, Jeonnam wild catfish; WJB, Jeonbuk wild catfish; WKN, Gyeongnam wild catfish; Cultured, cultured from Korea. 


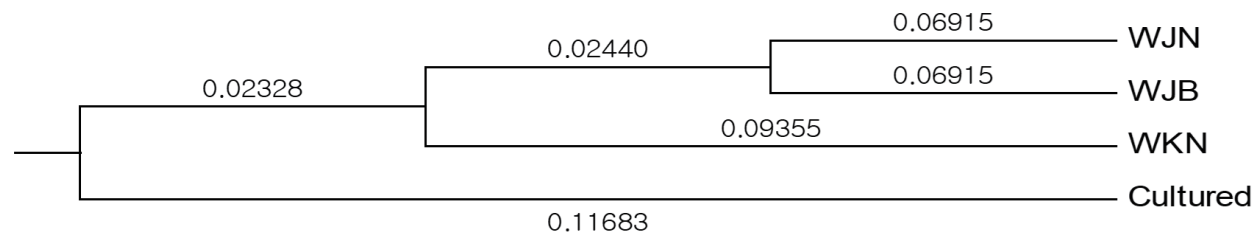

Fig. 2. The four populations were clustered using the UPGMA method based on the $D_{C E}$ genetic distances. WKN, wild from Kyungnam, Korea; KJN, wild from Jeonnam, Korea; WJB, wild from Jeonbuk, Korea; Cultured, cultured from Korea; UPGMA unweighted pair group with the arithmetic mean.

catfish studies to boost catfish fry release businesses. It has been hypothesized that the genetic similarity is related to the influence of artificially joined broodstock. In contrast, the cultured group continued its own production without the introduction of new wild broodstock, and therefore they are considered to be genetically distant from the wild group. Similar results have been reported with cultured carp (Ma et al., 2006; Mondol, 2006).

In conclusion, this study was conducted to analyze the diversity of wild and cultured catfish in Korea and the relationship between groups, using microsatellite markers. It was confirmed that the genetic diversity of wild and cultured catfish was well maintained; the wild and cultured groups were genetically distant. In the case of the wild group, diversity is maintained due to the continuous fry release by the local fish research institute. The variety of cultured catfish declined, and the genetic relationship of this group was distant from that of the wild group. It was found that the reduced diversity was caused by continued self-production without the addition of new wild broodstock. This can lead to a greater genetic diversity decline in cultured catfish over the next generation; continuous genetic diversity monitoring is necessary to maintain aquaculture productivity and to develop a sustainable aquaculture industry. To determine the actual effects of the release of wild catfish, paternity analyses are warranted, using microsatellite markers with fins of parent fish that participated in the production of seeds. This study can be used as a basis for aquaculture program development and breeding research.

\section{REFERENCES}

Alam MS, Islam MS (2005) Population genetic structure of Catla catla (Hamilton) revealed by microsatellite DNA markers. Aquaculture 246:151-160.

Allendorf FW, Phelps SR (1980) Loss of genetic variation in a hatchery stock of cutthroat trout. Trans Am Fish Soc 109:537-543.

An HS, Lee JW, Dong CM (2012) Population genetic structure of Korean pen shell (Atrina pectinata) in Korea inferred from microsatellite marker analysis. Genes Genom 34:681-688.

Beardmore AL, Mair CG, Lewis RI (1997) Biodiversity in aquatic systems in relation to aquaculture. Aquac 28:829-839.

Biba A, Hoda A, Vardhami E, Bozgo V (2015) Genetic diversity of common carp from Shkodra Lake based on microsatellite markers. Livestock Res Rural 27:79.

Carvalho GR, L Hauser (1994) Molecular genetics and the stock concept in fisheries. Rev Fish Biol Fish 4:326-350.

Cavalli-Sforza LL, Edwards AWF (1967) Phylogenetic analysis: Models and estimation procedures. Evolution 21:550-570.

Ghelichpour M, Shabani A, Shabanpour B (2013) Microsatellite variation and genetic structure of 
common carp (Cyprinus carpio) populations in gomishan bay and gorgonroud river (South East of Caspian Sea). Int J Acquat Biol 1:22-7.

Goudet J (2001) FSTAT, a program to estimate and test gene diversities and fixation indices (version 2.9.3). Available from: http://www.unil.ch/izea/softwares/fstat.html. Access at Nov 23, 2020.

Kalinowski ST, Taper ML, Marshall TC (2007) Revising how the computer program CERVUS accommodates genotyping error increases success in paternity assignment. Mol Ecol 16:10991106.

Kim EM, Kang HS, Kang JH, Kim DG, An CM, Lee HW, Park JY (2015) Genetic relationships of sandfish (Arctoscopus japonicas) from five different areas of Korea and Japan based on mitochondrial DNA and microsatellite analyses. Korean J Life Sci 25:1204-1213.

Kim DS, Kim IB, Huh HT, Park IS (1988) Cytogenetic analysis of catfish, Silurus asotus (Teleostomi: Siluriformes). Ocean Res 10:33-37.

Kim JE, Lee YM, Lee JH, Noh JK, Kim HC, Park CJ, Park JW, Kim KK (2014) Development and validation of single nucleotide polymorphism (SNP) markers from an expressed sequence tag (EST) database in Olive flounder (Paralichthys olivaceus). Dev Reprod 18:275-286.

Kim JU (2018) Genetic breeding of israeli carp (Cyprinus carpio) using microsatellite markers. Ph.D. Dissertation, Kyungsung University, Busan, Korea.

Kim JE, Kim MH, Im JH, Choi HS, Lee JH (2016) Genetic variability comparison of wild and cultured Far Eastern catfish (Silurus asotus) using microsatellite DNA marker. Korean J Fish Aquat Sci 2016.05:70-70.

Kincaid HL (1983) Inbreeding in fish populations used for aquaculture. Aquaculture 33:215-227.

Kohlmann K, Gross R, Murakaeva A, Kersten P (2003) Genetic variability and structure of common carp (Cyprinus carpio) populations throughout the distribution range inferred from allozyme, microsatellite and mitochondrial DNA markers. Aquat Living Resour 16:421-431.

Lim SG, Kim KS, Kang YJ, Kim EO, Son MH, An CM, Kim KW, Cho YC, Kim KD (2012) Evaluation of experimental extruded pellets and commercial extruded pellets for Far Eastern catfish Silurus asotus. Korean J Fish Aquat Sci 45:139-145.

Liu N, Chen L, Wang S, Oh S, Zhao H (2005) Comparison of single-nucleotide polymorphisms and microsatellites in inference of population structure. BMC Genet 6:S26.

Liu ZJ, Cordes JF (2004) DNA marker technologies and their applications in aquaculture genetics. Aquac 238:1-37.

Ma HY, Yue YS, Guo JF, Gong WH, Wang H (2006) Microsatellite marker analysis of genetic diversity and phylogenetic relationships in three populations of Cyprinus carpio L. Shandong province.J Lake Sci 18:655-660.

Mondol MRK, Islamz MS, Alam MS (2006) Characterization of different strains of common carp (Cyprinus carpio L.) (Cyprinidae, Cypriniformes) in Bangladesh using microsatellite DNA markers. Genet Mol Biol 29:626-633.

National Statistical Office of Korea (2020) 2019 Fishery production trend survey results. Available from: http://kostat.go.kr/portal/korea/kor_nw/1/1/index.board?bmode=read\&aSeq=381312. Access at Nov 23, 2020.

Park IS (2019) The anesthetic effects of clove oil and MS-222 on Far Eastern catfish, Silurus asotus. Dev Reprod 23:183-191.

Park IS, Im JH (2001) Determination of the temperature-dependent index of mitotic interval ( $\left.\tau_{0}\right)$ for chromosome manipulation in far eastern catfish Silurus asotus. Korean J Ichthyol 13:85-88.

Raymond M, Rousset F (1995) GENEPOP (Version 1.2): population genetic software for exact test of ecumenicism.J Hered 86:248-249.

Rousset F (2008) GENEPOP '007: a complete re-implementation of the genepop software for 
windows and linux. Mol Ecol Resour 8:103-106.

Sekino M, Sugaya T, Hara M, Taniguchi N (2004) Relatedness inferred from microsatellite genotypes as a tool for broodstock management of Japanese flounder Paralichthys olivaceus. Aquaculture 233:163-172.

Tamura K, Peterson D, Peterson N, Stecher G, Nei M, Kumar S (2011) MEGA5: molecular evolutionary genetics analysis using maximum likelihood, evolutionary distance, and maximum parsimony methods. Mol Biol Evol 28:2731-2739.

Weber JL, May PE (1989) Abundant class of human DNA polymorphisms which can be typed using the polymerase chain reaction. Am J Hum Genet 44:388-396.

Xie BM, Shao F, Zhang Y, Peng Z (2015) Development and characterization of 21 novel microsatellite markers for the Amur catfish (Silurus asotus Linnaeus, 1758). J Appl Ichthyol 31:917-918. 
